\title{
SUBTASK 2.2 - CREATING A NUMERICAL TECHNIQUE FOR MICROSEISMIC DATA INVERSION
}

Final Report

(for the period of March 30, 2008, through June 30, 2009)

Prepared for:

AAD Document Control

U.S. Department of Energy

National Energy Technology Laboratory

626 Cochrans Road

PO Box 10940, MS 921-107

Pittsburgh, PA 15236-0940

Cooperative Agreement No. DE-FC26-08NT43291

Project Manager: Steven Markovich

Prepared by:

Anastasia A. Dobroskok

Yevhen I. Holubnyak James A. Sorensen

Energy \& Environmental Research Center

University of North Dakota 15 North 23rd Street, Stop 9018 Grand Forks, ND 58202-9018 


\section{EERC DISCLAIMER}

LEGAL NOTICE This research report was prepared by the Energy \& Environmental Research Center (EERC), an agency of the University of North Dakota, as an account of work sponsored by the U.S. Department of Energy. Because of the research nature of the work performed, neither the EERC nor any of its employees makes any warranty, express or implied, or assumes any legal liability or responsibility for the accuracy, completeness, or usefulness of any information, apparatus, product, or process disclosed or represents that its use would not infringe privately owned rights. Reference herein to any specific commercial product, process, or service by trade name, trademark, manufacturer, or otherwise does not necessarily constitute or imply its endorsement or recommendation by the EERC.

\section{DOE DISCLAIMER}

This report was prepared as an account of work sponsored by an agency of the United States Government. Neither the United States Government, nor any agency thereof, nor any of their employees, makes any warranty, express or implied, or assumes any legal liability or responsibility for the accuracy, completeness, or usefulness of any information, apparatus, product, or process disclosed, or represents that its use would not infringe privately owned rights. Reference herein to any specific commercial product, process, or service by trade name, trademark, manufacturer, or otherwise does not necessarily constitute or imply its endorsement, recommendation, or favoring by the United States Government or any agency thereof. The views and opinions of authors expressed herein do not necessarily state or reflect those of the United States Government or any agency thereof.

This report is available to the public from the National Technical Information Service, U.S. Department of Commerce, 5285 Port Royal Road, Springfield, VA 22161; phone orders accepted at (703) 487-4650. 


\title{
SUBTASK 2.2 - CREATING A NUMERICAL TECHNIQUE FOR MICROSEISMIC DATA INVERSION
}

\begin{abstract}
Geomechanical and geophysical monitoring are the techniques which can complement each other and provide enhancement in the solutions of many problems of geotechnical engineering. One of the most promising geophysical techniques is passive seismic monitoring. The essence of the technique is recording the acoustic signals produced in the subsurface, either naturally or in response to human activity. The acoustic signals are produced by mechanical displacements on the contacts of structural elements (e.g., faults, boundaries of rock blocks, natural and induced fractures). The process can be modeled by modern numerical techniques developed in geomechanics. The report discusses a study that was aimed at the unification of the passive seismic monitoring and numerical modeling for the monitoring of the hydraulic fracture propagation. The approach adopted in the study consisted of numerical modeling of the seismicity accompanying hydraulic fracture propagation and defining seismic attributes and patterns characterizing the process and fracture parameters. Numerical experiments indicated that the spatial distribution of seismic events is correlated to geometrical parameters of hydrofracture. Namely, the highest density of the events is observed along fracture contour, and projection of the events to the fracture plane makes this effect most pronounced. The numerical experiments also showed that dividing the totality of the events into groups corresponding to the steps of fracture propagation allows for reconstructing the geometry of the resulting fracture more accurately than has been done in the majority of commercial applications.
\end{abstract}




\section{TABLE OF CONTENTS}

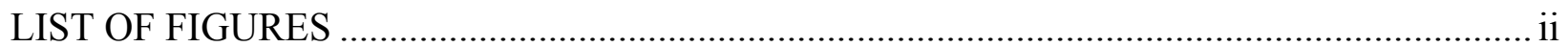

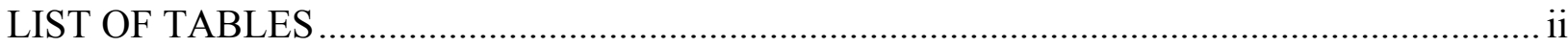

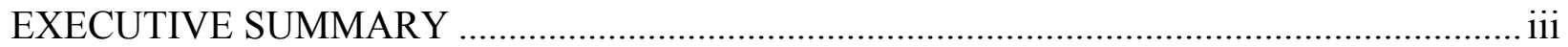

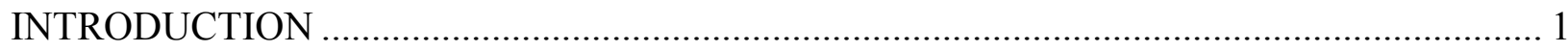

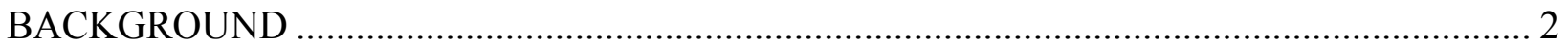

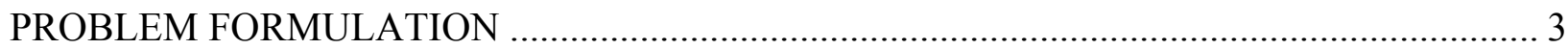

DEVELOPMENT OF THE METHODOLOGY FOR MICROSEISMIC DATA

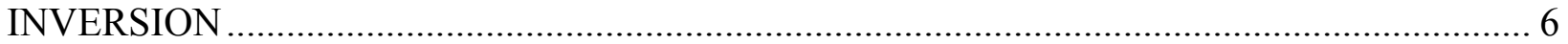

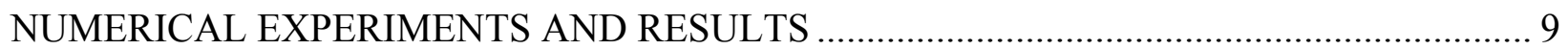

APPLICATION OF THE TOOL TO THE ACOUSTIC EMISSION DATA OBTAINED IN

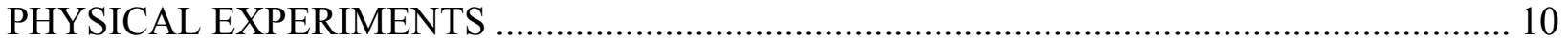

APPLICATION OF THE TOOL TO THE MICROSEISMIC DATA OBTAINED IN

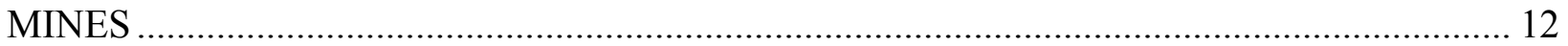

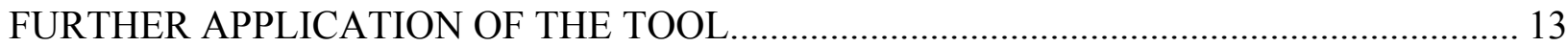

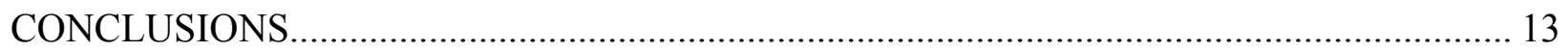

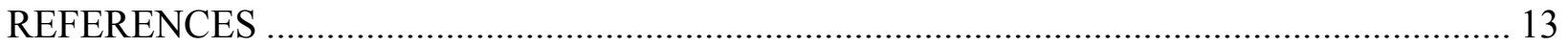

MICROSEIMIC DATA RECORDED IN A COAL MINE ..........................................Appendix A 


\section{LIST OF FIGURES}

1 Dependence of the frequency-magnitude type for hydrofracture .................................. 7

2 Spatial distribution of simulated seismic events occurred during fracture

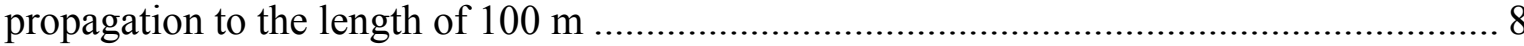

3 Distribution of events per 10 meters of fracture propagation with respect to

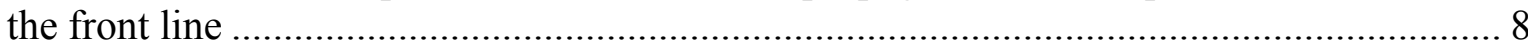

$4 \quad$ Reconstructed fracture plane and spatial distribution of the events............................. 11

5 Grouping of the seismic events in steps of fracture propagation ................................ 11

\section{LIST OF TABLES}

1 Parameters Used in the Approximated Analytical Solution............................................. 5 


\section{SUBTASK 2.2 - CREATING A NUMERICAL TECHNIQUE FOR MICROSEISMIC DATA INVERSION}

\section{EXECUTIVE SUMMARY}

Joining geomechanical and geophysical monitoring is an important direction in geoengineering and has stimulated the development of appropriate theoretical and numerical techniques for decades. The techniques allow geomechanical and geophysical approaches to complement each other by eliminating the shortcomings and unifying the advantages. The development of the techniques has resulted in the creation of the basis that will allow for the unification. The next step is the application of the developed multidisciplinary approach to the specific problems of geotechnical engineering. One of the most important geotechnical problems is the characterization of the subsurface system and understanding the processes taking place in the system. The solution of the problem is complicated by the complexity and the limited access to the system. A variety of geophysical techniques are presently employed in the attempt to resolve the problem. One of the most promising techniques is passive seismic monitoring. The essence of the technique is recording the acoustic signals produced in the subsurface either naturally or in response to human activity. The acoustic signals are produced by mechanical displacements on the contacts of structural elements (e.g., faults, boundaries of rock blocks, natural and induced fractures). The process can be modeled by modern numerical techniques developed in geomechanics. The report discusses the study which was aimed at the unification of the passive seismic monitoring and numerical modeling. In particular the unification targeted development of a technique for the inversion of passive seismic data recorded during hydraulic fracture propagation.

The approach adopted in the study consisted of numerical modeling of the seismicity accompanying hydraulic fracture propagation and defining seismic attributes and patterns characterizing the process and fracture parameters. Numerical experiments indicated that the spatial distribution of seismic events is correlated to geometrical parameters of hydrofracture. Namely, the highest density of the events is observed along fracture contour, and projection of the events to the fracture plane makes this effect most pronounced. Thus determining the plane with the best defined grouping of the events helps in finding the fracture plane. The numerical experiments also showed that dividing the totality of the events into groups corresponding to the steps of fracture propagation allows for reconstructing the geometry of the resulting fracture more accurately than it has been done in the majority of commercial applications.

The described features provide the basis of the methodology for the inversion of the microseismic data. In particular, the authors suggested a strip ray scanning (SRS) technique for data interpretation and compared it to the principal component analysis (PCA) technique suggested by other authors. It appears that when applied to the totality of seismic events, both methods are capable of catching the fracture plane with reasonable accuracy. Still, the totality of event locations, even projected to this best-fit plane, does not provide unambiguous estimation of the fracture sizes. To find the latter, it is better to use statistically significant groups of events occurring on time steps. Application of the PCA and SRS to these groups tends to delineate the fracture front and the direction of the front propagation in time. It is concluded that the PCA and 
SRS methods may complement each other when analyzing the totality of the events, while the SRS method looks a proper tool to trace the fracture front on time steps and the length of a fracture. Both techniques are implemented into a computer code. The code was used for the analysis of acoustic emission data recorded in laboratory experiments and miscroseismic data from mines and allowed to reasonably reconstruct the geometry of the mine and the fracture created in physical experiments. The technique has a potential to be extended for the case of hydrofracture branching and for characterizing fluid paths in the subsurface reservoirs. 


\section{SUBTASK 2.2 - CREATING A NUMERICAL TECHNIQUE FOR MICROSEISMIC DATA INVERSION}

\section{INTRODUCTION}

The growing demand for and depleting supply of fossil fuels is facilitating the shift of many exploration and production activities toward unconventional reserves. Although "unconventionals" have big potential, experts believe that significant achievements are impossible without revolutionary technologies. The technologies are also in demand in rapidly developing carbon dioxide $\left(\mathrm{CO}_{2}\right)$ storage and geothermal generation sectors. One of the key components in the development of the reserves is better characterization and understanding of the subsurface system. A variety of geophysical, geostatistical, and analytical techniques have been employed in attempts to improve current technologies. Being quite sophisticated, the techniques often provide data that are difficult to interpret. Continuous need in meaningful interpretation has recently drawn much attention to passive seismic monitoring (Liu et al., 2006; Trifu, 2008). Since its application requires proper interpretation of seismic data, some techniques to reach this goal have been developed and commercialized, i.e., mapping of a hydraulically induced fracture. Still further improvements are required for microseismic data interpretation. A path toward these improvements may involve complementing field observations with numerical simulation of seismicity. This serves to cross-fertilize seismology and computational rock mechanics by employing the advantages of the two disciplines.

Passive seismicity is produced by mechanical displacements on the surfaces of the discontinuities present in the reservoir. As such, passive seismicity can be modeled by employing geomechanical approaches. Different applications of passive seismic monitoring have been actively discussed recently (Maxwell and Young, 1996; Mahrer, 1999; Urbancic and Trifu, 2000; Maxwell et al., 1993; Daniels et al., 2007). A variety of seismic parameters such as seismic deformation, energy partitioning between compressional and shear waves, and distribution of seismic energy release are analyzed in the cited literature. Still, the majority of the commercial applications do not dwell on the details of the seismic process. In these applications (e.g., hydraulic fracturing), the zone affected by a certain process is defined by analyzing the location of a cloud of seismic events. For hydraulic fracture applications, this means that the orientation, exact location, and trajectory of the fracture stay quite uncertain. Thus it is desirable to improve the analysis by employing numerical models capable of operating with a bigger array of the parameters available from field observations.

The current report discusses the way of interpreting the data of passive seismic monitoring as it applies to the problem of hydraulic fracturing. Understanding hydrofracture geometry is important for the solution of such engineering problems as building a rigorous model of a reservoir under consideration or designing best completion techniques. 


\section{BACKGROUND}

The methodology used in the current study extends the approach initiated by Salamon (1993) for mining applications. It has been used and developed during the last decade (e.g., Napier, 2001; Sellers and Napier, 2001; Spottiswood, 2001). Recently, general principles and a simple model for numerical simulation of seismic and aseismic events have been suggested and used in codes adjusted for mining practices (Linkov, 2005, 2006).

The process of hydraulic fracture propagation is similar to mining in that it causes changes in the in situ state of the system and triggers microseismic events. The processes differ by the time-dependent process governing the stress change. In hydraulic fracturing, it is the changing of fracture geometry over time (propagation), dependent on fluid viscosity, fluid loss, rock rigidity, etc. In mining problems, the changes in time are primarily defined by prescribed mining steps that change the geometry of the mined area. Consequently, a model for simulating events accompanying hydraulic fracturing should include a dependence of the fracture geometry and liquid pressure on time.

A particular development of a microseismic process depends on such features as structure and properties of rock, in situ stresses, pressure of the pumped fluid, and the resulting geometry of a hydraulic fracture. Thus inversion of microseismic data can provide information regarding these features, which are of importance in engineering problems. The proposed approach is suited for the inversion because of the employed numerical procedures. They provide robust calculations of parameters, which can be measured by using modern technologies.

The approach is based on studying a system of statistically seeded flaws under the influence of time-dependent processes. As mentioned, in the case of hydraulic fracture, the processes are movement of the fracture front and changes in fracture net pressure, which lead to stress redistribution around the fracture. As a result, tractions at surfaces of some of the flaws reach tensile or shear strength. This triggers either seismic or aseismic events. After an event, its source experiences displacement discontinuity. The displacement discontinuity, in turn, influences the stresses and may result in a chain of events.

Accounting for the changes in the geometry of the fracture, net pressure and displacement discontinuities of activated flaws are accomplished by utilizing the 3D hypersingular boundary integral equations (Linkov, 2002). The main advantage of the equations is that they employ the needed values: displacement discontinuities and tractions, both on the fracture and the activated flaws. Numerical implementation is performed in frames of the hypersingular boundary element method (BEM).

The numerical technique developed has the following advantages:

- Ease of studying up to a million of defects

- Employs the elasticity-softening-creep (ESC) model for flaws, which allows one to simulate both unstable (seismic) and stable (aseismic, damping, or accelerating) events 
- Employs the hypersingular BEM for the effective solution of problems involving changes in geometry and multiple displacement discontinuities

The output of numerical simulations is formulated in terms of the following:

- Solid mechanics, such as stresses, tractions, strains, and displacements

- Seismology, such as time, location, seismic moment, energy, velocity or acceleration for a single event and temporal and spatial distributions, and dependence frequencymagnitude for a set of simulated events.

\section{PROBLEM FORMULATION}

The subject of the current study is seismicity accompanying hydraulic fracture. The following discusses the problem formulation for the simulation of seismicity and modifications needed to account for hydraulic fracturing.

Simulation of the seismicity follows the procedure suggested in Linkov (2006). Initially the geometry of the system is prescribed; this includes the geometry of structural features of the rock such as layers, faults, and openings. The initial model is complemented by mechanical properties of the media and in situ stresses. For the purpose of simulating seismic and aseismic events, a number of flaws modeled by cracks are seeded in the domain considered. The locations, orientation, and sizes of the flows are statistically distributed throughout the domain. A seismic or aseismic event occurs on a flow as a result of the mutual displacement of its surfaces. The particular type of event depends on the properties of the contact, i.e., on its tensile and shear strength. The properties can be prescribed using the ESC model (Linkov, 2006). The flows for which the strength is exceeded for the initial state of stress are considered inactive and excluded from further analysis.

After the initial geometry of the system and in situ stresses are prescribed, the timedependent process that causes changes in the stress state must be accounted for. In the present study, the process is hydraulic fracture propagation. The process influences the stress state in the vicinity of the fracture and causes some of the flows to reach their strengths. Then a seismic or aseismic event occurs on the flow. These events are numerically simulated in the manner described on the steps of fracture propagation, and the flows that experienced a seismic or aseismic event become inactive. The output of the simulation contains the information on the location, time of occurrence, and features of the simulated events.

During hydraulic fracturing, two of the changing parameters are i) the geometry of the system and ii) pore pressure distribution (Dobroskok and Linkov, 2008). Indeed, during hydraulic fracturing, two surfaces are created where intact rock was previously, and fluid flow into the newly created fracture and losses of the fluid into the formation redistribute pore pressure in the vicinity of the fracture. However, the opening of the fracture and displacements on its surfaces are usually negligible. The process governing the development of seismicity is likely to be pore pressure redistribution, which is most pronounced around the fracture. Stress 
concentration at the tip of the fracture may influence seismicity near the tip. Thus it can be suggested that the majority of the events will occur in the close vicinity of the fracture and localize around its front. To check these suggestions, we conducted numerical experiments. To do so, we used the approximated analytical solution presented in Linkov (2008). The solution (Equation 1) couples changes in fluid flow with fracture propagation. It is written in terms of dimensionless parameters described in Table 1.

$$
\begin{aligned}
& \Delta p_{D}\left(t_{D}, x_{2}\right)=\frac{160}{3 \pi} w_{D} \frac{h_{D}}{a_{D}} \frac{2}{\pi}\left[1+1.515 \exp \left(-1.15 r_{D}\right)\right]\left(1-\frac{x_{2}}{L}\right)^{0.25}, \\
& w_{D}=0.2 \pi\left[\frac{L_{D}=0.48 t_{D}^{0.552},}{1+1.515 \exp \left(-1.15 r_{D}\right)} L_{D}\right]^{0.25}
\end{aligned}
$$

According to the chosen approximation and Equation 1, the net pressure, $\Delta p=p+t_{n 0}$, is about constant along the fracture. Herein, $p$ is the fluid pressure in the fracture $(p>0)$ and $t_{n 0}=\sigma_{33}$ is the normal traction resulting from the in situ stresses on the crack surface $\left(\sigma_{33}<0\right)$. Fracture propagation is possible only if the average net pressure is positive $(\Delta p>0)$. Normally in hydraulic fracture problems, the ratio $\Delta p /\left|t_{n 0}\right|$ does not exceed 0.3 . This presents a specific feature of these problems as compared with mining problems, where $p=0$ : in the latter problems, the induced traction is negative and is of the order of in situ stresses. Thus it can be suggested that in hydraulic fracture, the portion of seismic events and their energy are notably less than in analogous mining problems. The study considered a fracture of the length $L(t)$, height $h$, and width $w(L)$ propagating in a rock mass containing a system of natural fractures. The following assumptions were made for certainty:

- The origin $O$ is located at the depth $H$ from the earth's surface in the middle of the fracture height $h$.

- Fracture height $h$ is at least three times less than the distance to the surface $H$.

- The axes $x_{1}, x_{2}$, and $x_{3}$ are directed vertically, to the east and to the north, respectively. These directions are the directions of principal stresses $\left(\sigma_{11}>\sigma_{22}>\sigma_{33}\right)$.

- The volume with seeded flaws is taken as a parallelepiped, with the size $X_{1}$ of $5 h$ in the vertical direction, $8 h$ in the eastern direction $\left(X_{2}\right)$, and $2 h$ in the northern direction $\left(X_{3}\right)$. From experience, we expect that the height $h$ does not exceed $100 \mathrm{~m}$, while the final length $L_{f}$ of the fracture is normally less than $150 \mathrm{~m}$, and thus the chosen volume is the one in which the influence of the final fracture will be notable. 
Table 1. Parameters Used in the Approximated Analytical Solution

\begin{tabular}{|c|c|}
\hline & Description \\
\hline$a_{D}$ & $\begin{array}{l}\text { Normalized length of the small fracture side }\left(a_{D}=h_{D} \text { if } h<L ; a_{D}=L_{D} \text { if }\right. \\
\qquad h>L)\end{array}$ \\
\hline$b_{D}$ & $\begin{array}{l}\text { Normalized length of the large fracture side }\left(b_{D}=L_{D} \text { if } h<L ; b_{D}=h_{D} \text { if }\right. \\
\qquad h>L)\end{array}$ \\
\hline$C$ & Fluid loss coefficient \\
\hline$E$ & Young's modulus of the rock \\
\hline$G$ & Shear modulus of the rock \\
\hline$h=h_{0}$ & Fracture height assumed to be constant \\
\hline$h_{D}=h / L_{n}$ & \\
\hline$L_{n}=\pi\left[\frac{(1-v) \mu q_{0}{ }^{5}}{256 G C^{8} h_{0}{ }^{4}}\right]^{1 / 3}$ & Characteristic normalizing fracture length \\
\hline$L, L_{D}=L / L_{n}$ & Fracture length \\
\hline$p_{n}=\frac{3 \pi}{32}\left[\frac{2 \mu G^{2} q_{0}^{2}}{(1-v)^{2} C^{2} h_{0}^{4}}\right]^{1 / 3}$ & Characteristic normalizing pressure \\
\hline$\Delta p, \Delta p_{D}=\Delta p / p_{n}$ & Net pressure \\
\hline$q_{0}$ & Constant inflow rate \\
\hline$r_{D}=a_{D} / b_{D}$ & Ratio of the small to large fracture side lengths \\
\hline$t_{n}=\pi^{2}\left[\frac{(1-v) \mu q_{0}^{2}}{32 G C^{5} h_{0}}\right]^{2 / 3}$ & Characteristic normalizing time \\
\hline$t, t_{D}=t / t_{n}$ & Time \\
\hline$w_{n}=\pi^{2}\left[\frac{16(1-v) \mu q_{0}{ }^{2}}{G C^{2} h_{0}}\right]^{1 / 3}$ & Characteristic normalizing fracture width \\
\hline $\mathrm{w}, w_{D}=w / w_{n}$ & Fracture width \\
\hline$x_{2}$ & Coordinate axis coincident with the direction of fracture propagation \\
\hline$\mu$ & Fluid viscosity \\
\hline$v$ & Poisson ratio of the rock \\
\hline
\end{tabular}

- The natural fractures are modeled by square flaws with uniform distribution of the coordinates, dip, and strike angles, with exponential distribution of the length $l$ of the square side and density $\xi$, defined as in Linkov (2005).

- The mechanical properties of the flaws are described by the ESC model (Linkov, 2005). Corresponding numerical parameters are tensile strength $t_{0}$, cohesion $c_{0}$, friction angle $\rho$, softening modulus $M$, elasticity modulus $E_{l}$ of Kelvin's element, and its retardation time $t_{r}$, which substitutes for viscosity $\left(t_{r}=\eta / E_{l}\right)$. To simplify the output analysis, we set $t_{0}, c_{0}, \rho, M / E_{l}$ and $t_{r}$ constant. The distribution of the softening modulus 
is prescribed as $\frac{M}{K_{S}}=a_{r}+b_{r} f_{r}$. Herein, $K_{S}=0.92 E / l$ is the shear rigidity ${ }^{\dagger}$ of the rock with the Young's modulus $E$ with respect to a square flaw with the side $l ; f_{r}$ is the random variable uniformly distributed at the interval $[-1,1]$; and $a_{r}, b_{r}$ are parameters, serving to choose the statistical mean ratio of the simulated number $N_{A}$ of aseismic events to the number $N_{S}$ of seismic events: $N_{A} / N_{S}=\left(b_{r}-a_{r}+1\right) /\left(b_{r}+a_{r}-1\right)$, where $\left|a_{r}-b_{r}\right| \leq b_{r}$.

\section{DEVELOPMENT OF THE METHODOLOGY FOR MICROSEISMIC DATA INVERSION}

The problem described is formulated in a way that allows simulation of the seismicity accompanying the hydrofracturing process. Although the purpose of the project was to create the technique for the inversion of the data collected in the field, simulation of the process is a necessary step because it reveals the features of the process which can be used for the creation of the methodology. Thus the numerical experiments were conducted to define the features.

The following values of the parameters were used for simulations. Depth $H=500 \mathrm{~m}$; in situ stresses $\sigma_{11}=-7.5 \mathrm{MPa}, \sigma_{22}=-5.0 \mathrm{MPa}, \sigma_{33}=-4.0 \mathrm{MPa}$; the Young's modulus $E=20 \mathrm{GPa}$; Poisson ratio $v=0.25$; vertical fracture height $h=50 \mathrm{~m}$ and its final length is $L_{f}=100 \mathrm{~m}$; number of flaws $N=75000$; fracturing fluid viscosity $\mu=3 \cdot 10^{-8} \mathrm{MPa} \cdot \mathrm{sec}$, fluid loss coefficient $C=$ $1.510^{-4} \mathrm{~m} / V_{\mathrm{sec}}$; and constant inflow rate is $q_{0}=2 \mathrm{~m} / \mathrm{min}$. The mechanical properties of flaws, described by the ESC model, are as follows: tensile strength is zero, cohesion $c_{0}=0.1 \mathrm{MPa}$, friction angle $\rho=15^{0}, a_{r}=2.0, b_{r}=0.1$; and modulus $E_{l}$ and retardation time $t_{r}$ of the Kelvin element of the ESC model are arbitrary.

Calculations confirmed the suggestion that the number of seismic events and their energy are less than in analogous mining problems. Figure 1 shows dependencies of the frequencymagnitude type for hydrofracturing. The results of the similar mine simulations can be found in Linkov (2006). It should be noted that to simulate the same number of events, the number of flaws in the problem of hydrofracturing must be significantly (an order) greater than that in mining problems. Accordingly, the portion of the events is an order less than that when modeling a mining process.

In the graph (Figure 1), the abscissa presents decimal logarithm of the energy associated with the magnitude. The ordinate contains decimal logarithms of the relative number of events with the magnitude exceeding a given value. In accordance with the theoretical analysis given in Linkov (Linkov, 2005, 2006), the curve in its middle portion has a negative angular coefficient approximately equal to -0.5 . The curve is about horizontal for very small magnitudes and abruptly drops for large magnitudes. There were no simulated events with the magnitude exceeding -4 , that is, with energy greater than $100 \mathrm{~J}$. The energy is four orders less than that of

\footnotetext{
${ }^{\dagger}$ In (Linkov, 2005) the author missed the coefficient 4.0 in the equations for shear rigidity.
} 


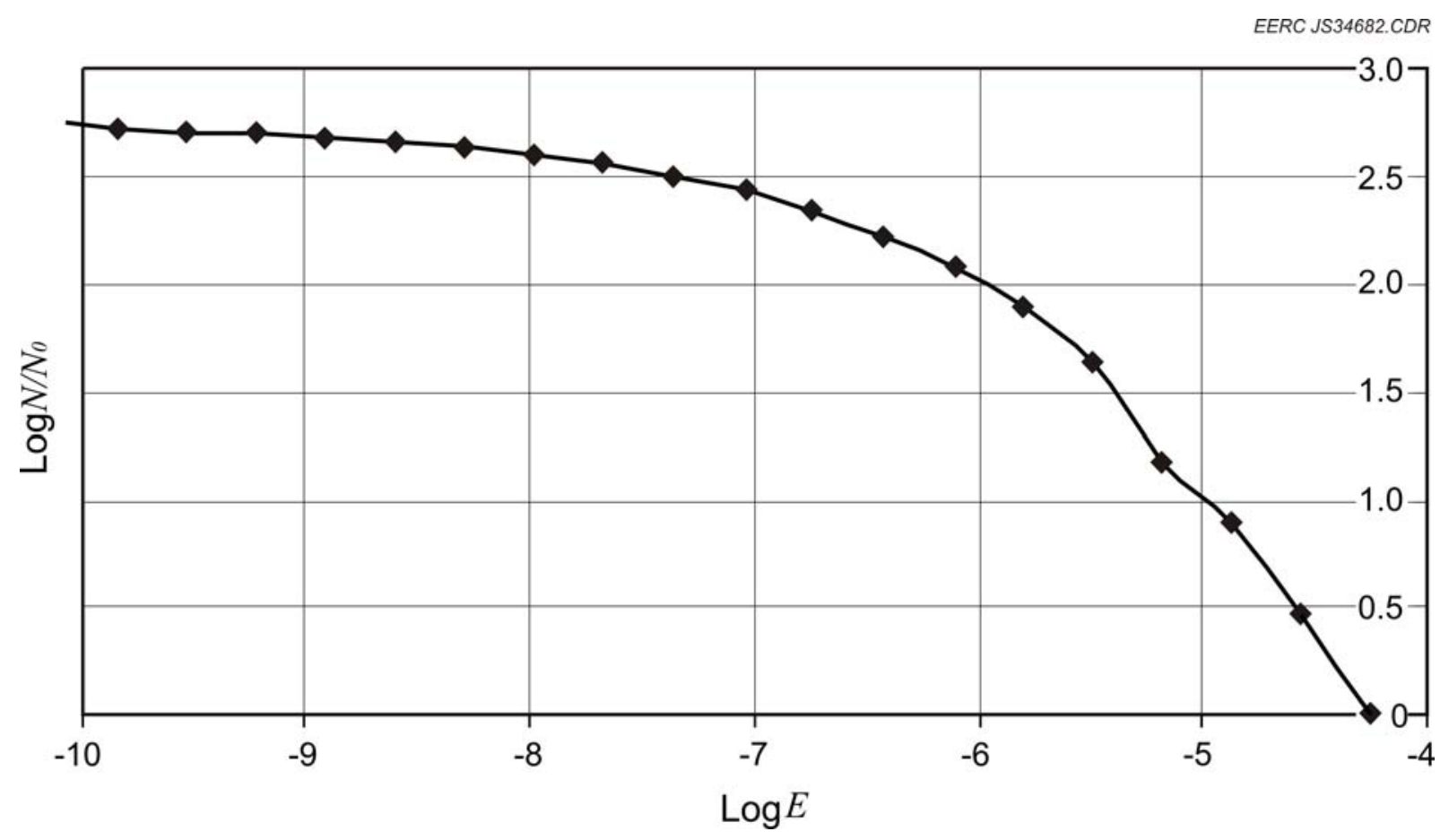

Figure 1. Dependence of the frequency-magnitude type for hydrofracture.

strong events (rockbursts) in deep mines. This implies that in agreement with the discussion in Wright (2007), only microseismic observations may be of practical value for hydraulic fracturing.

Finally, we would like to discuss the applicability of the results to hydrofracture monitoring. The goal of a monitoring program is to gain understanding of the geometry of the resulting fracture and find the zone of its influence on the fluid (oil, gas, or geothermal fluid)flow. Thus a part of the current study was focused on tracing seismicity on steps of hydraulic fracture propagation and trying to define processes capable of characterizing fracture geometry.

Figure 2 presents projections of the locations of the simulated events to the fracture plane. The dashed line shows the contour of the area with seeded flaws; the bold solid line is the contour of the fracture at its final position. It should be noted that most of the simulated events appeared within or in the nearest vicinity of the fracture. The highest density of the events is observed along its contour. Projections to other planes do not have such grouping. Hence, an appropriate analysis of the spatial distribution of the events may provide information on the orientation of the fracture plane.

Considering events appearing during a simulated step of fracture propagation (the step is taken $10 \mathrm{~m}$ ), as could be expected, most of the events appear in the vicinity of the moving front of the fracture. Figure 3 shows the tally of the events, occurred within two subsequent steps of 


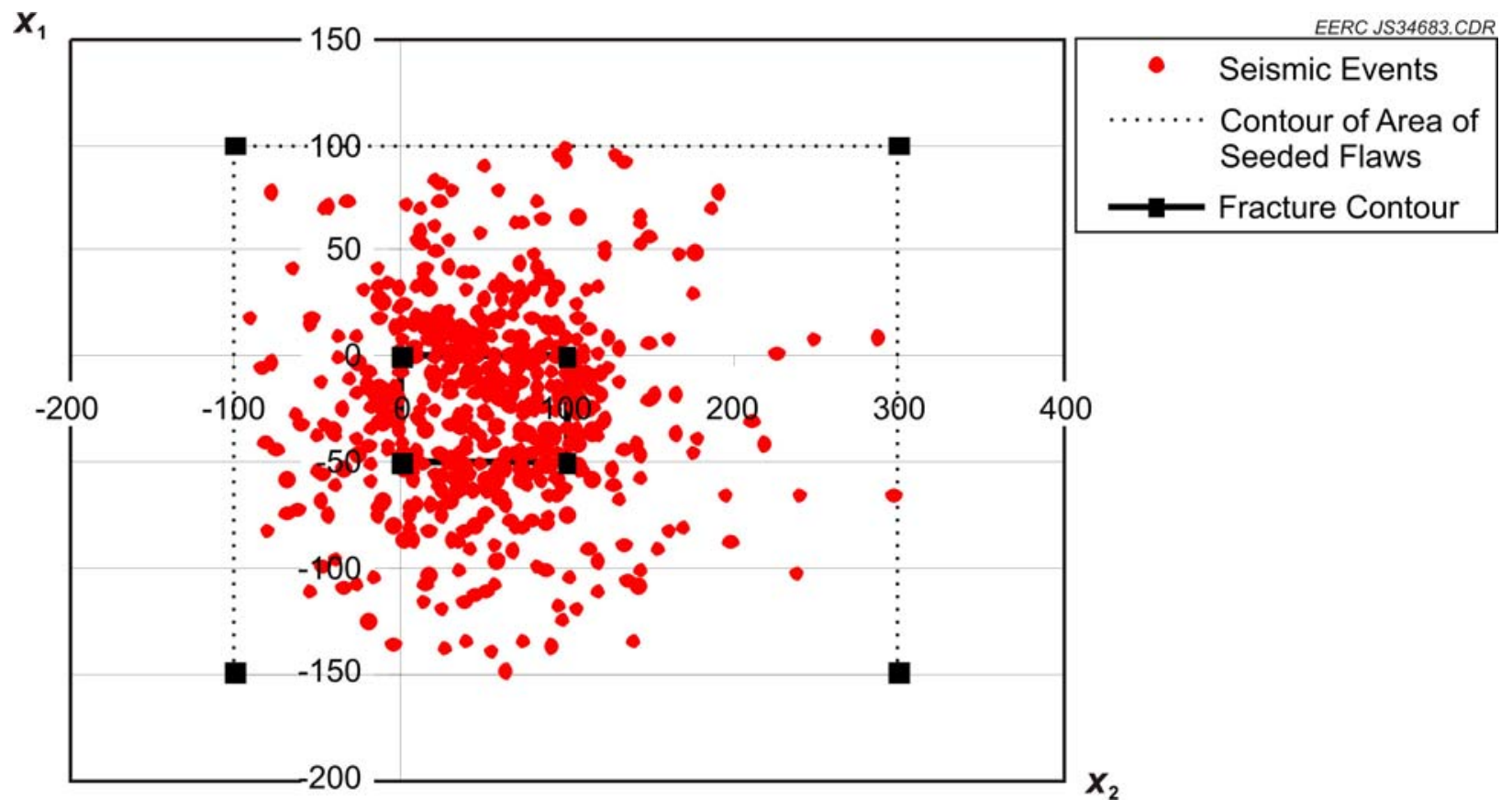

Figure 2. Spatial distribution of simulated seismic events occurred during fracture propagation to the length $100 \mathrm{~m}$.
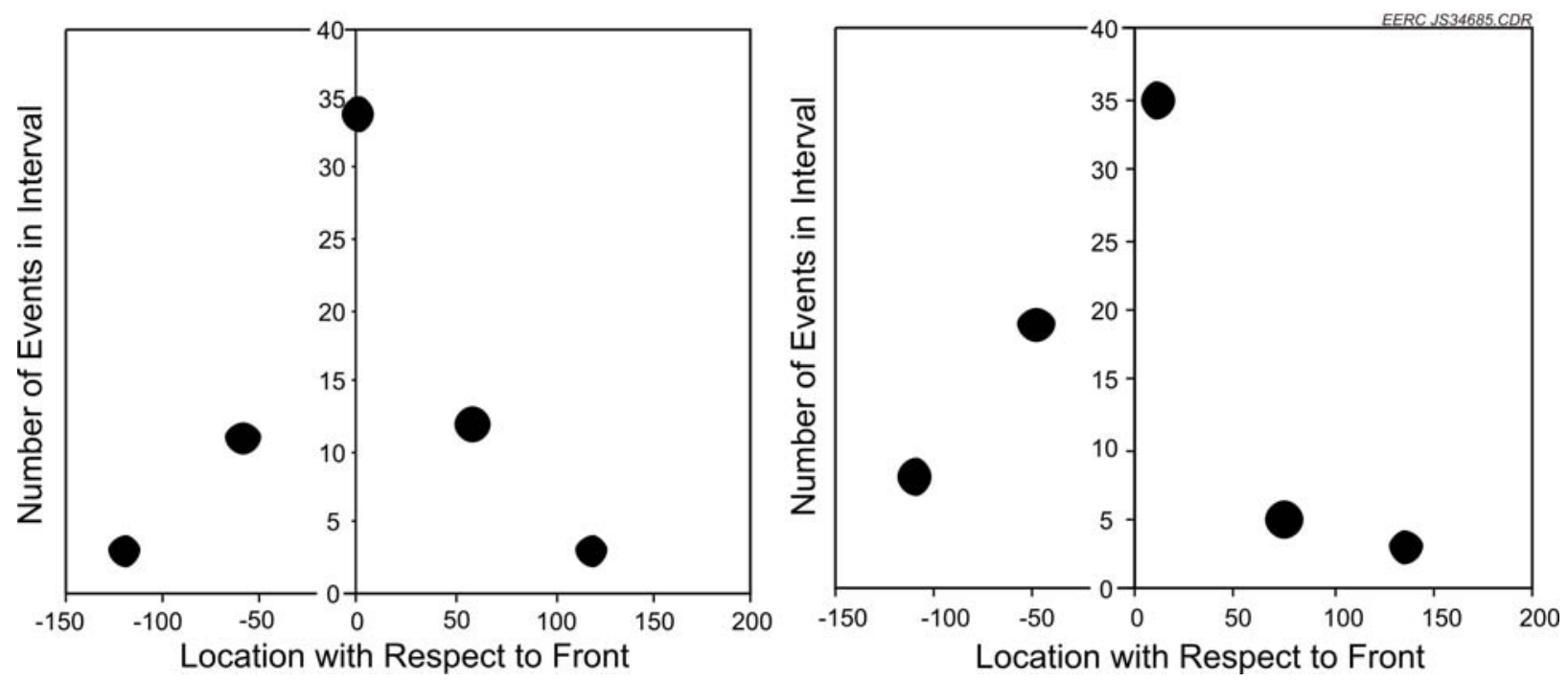

Figure 3. Distribution of events per 10 meters of fracture propagation with respect to the front line. 
fracture propagation, with respect to the front of the fracture propagation. We may see that, in general, the number of events ahead of the front does not differ significantly from their number behind the front. This means that in practice, the front line may be associated with the middle line of events, occurring per time needed for the fracture propagation of some 10 meters. At least half of the events are concentrated near the front line.

The discussion above indicates that two characteristics of fracture geometry, location of the front and orientation of the fracture plane, may be determined by analyzing seismic attributes. It can be argued that the results refer to the simple fracture geometry studied. In this regard, it would be interesting to study more complex fracture geometries. The model allows us to do such a study. However, it must be kept in mind that commonly technical issues do not allow for accurate mapping of spatial and temporal distribution of the events (King and Talebi, 2007). Thus we have to balance the accuracy of a geometrical scheme with that available or expected in field measurements. The dependences can be summarized as follows:

- Spatial distribution of seismic events is correlated to geometrical parameters of hydrofracture. Namely, the highest density of the events is observed along fracture contour, and projection of the events to the fracture plane makes this effect most pronounced. Thus determining the plane with the best-defined grouping of the events helps in finding the fracture plane.

- Dividing the totality of the events into groups corresponding to the steps of fracture propagation allows for determining the plane and direction of fracture growth and location of fracture front in steps. This allows for the reconstruction of the geometry of the resulting fracture more accurately than it has been done in the majority of commercial applications.

These dependences present the core of a technique developed in the project. The authors called the technique strip ray scanning (SRS), reflecting the fact that 1) the analysis is conducted for the groups of the events, with groups corresponding to time steps and, consequently, to the steps of fracture propagation, and b) the search for the fracture front and plane is conducted by scanning among numerous possible planes. It should be noted that the analysis can also be conducted by applying alternative techniques such as principal component analysis (PCA) (Du et al., 2008). The comparison of the techniques is discussed in the section on numerical experiments and results.

\section{NUMERICAL EXPERIMENTS AND RESULTS}

The numerical simulation of the seismicity accompanying hydraulic fracture propagation described in the previous section resulted in the creation of the following numerical procedure for microseismic data inversion:

- The events recorded in the field (or generated synthetically) are combined into statistically significant groups corresponding to time steps (steps of fracture propagation). 
- The events are projected to the planes perpendicular to the axis of the wellbore. The angles of the planes are recorded from the north and vary with a prescribed precision. This produces sets of projections of the events.

- The plane in which the projection of the events is the closest to an ellipse with the minimum ratio of the lengths of the short and long axes is chosen as the fracture plane. An additional check on the plane can be conducted by analyzing the projection of the events to the orthogonal plane: the ratio of the length of the ellipse axes should be close to the unit. This procedure is executed for both the totality of the events and for the groups of the events.

- In the chosen plane, the direction of front movement is found using the procedure similar to the one described in the previous paragraph.

- The location of the fracture front is found by analyzing the distribution of the events along the line of fracture propagation. The front is assumed to be located at the location of the highest density of the events.

- Repeating the procedure for each group of the event, the complete geometry of the fracture is reconstructed.

The procedure was applied first to the synthetic data obtained by simulating fracture propagation. The projections of the events to the plane found using the described procedure are shown in Figure 4. It can be seen that the majority of the events are located within a rectangle. The estimated angle of the plane deviated from the actual one by 2 degrees. Figure 5 illustrates the distribution of the seismic events obtained for the groups of events corresponding to the fifth and sixth steps of fracture propagation. The actual location of the fracture front is shown by solid lines. The picks of the distributions are in good agreement with the actual location of the front.

These experiments showed that the procedure developed provides reliable results for the inversion of the synthetic data.

\section{APPLICATION OF THE TOOL TO THE ACOUSTIC EMISSION DATA OBTAINED IN PHYSICAL EXPERIMENTS}

The procedure created for the inversion of the data was tested using acoustic emission (AE) data obtained in a laboratory. The laboratory data are confidential and were provided by Dr. Joseph Labuz, Professor of Civil Engineering at the University of Minnesota. The results of the physical experiment by Professor Labuz and the results of the analysis are to be published later. Thus this report does not discuss the physical experiment and the analysis of the data in detail. However, the results pertinent to the efficiency of the developed tool are discussed below.

Two sets of AE data corresponding to the physical experiments conducted in the laboratory were analyzed (Riedel and Labuz, 2006). Files with data contained only locations of the AE 


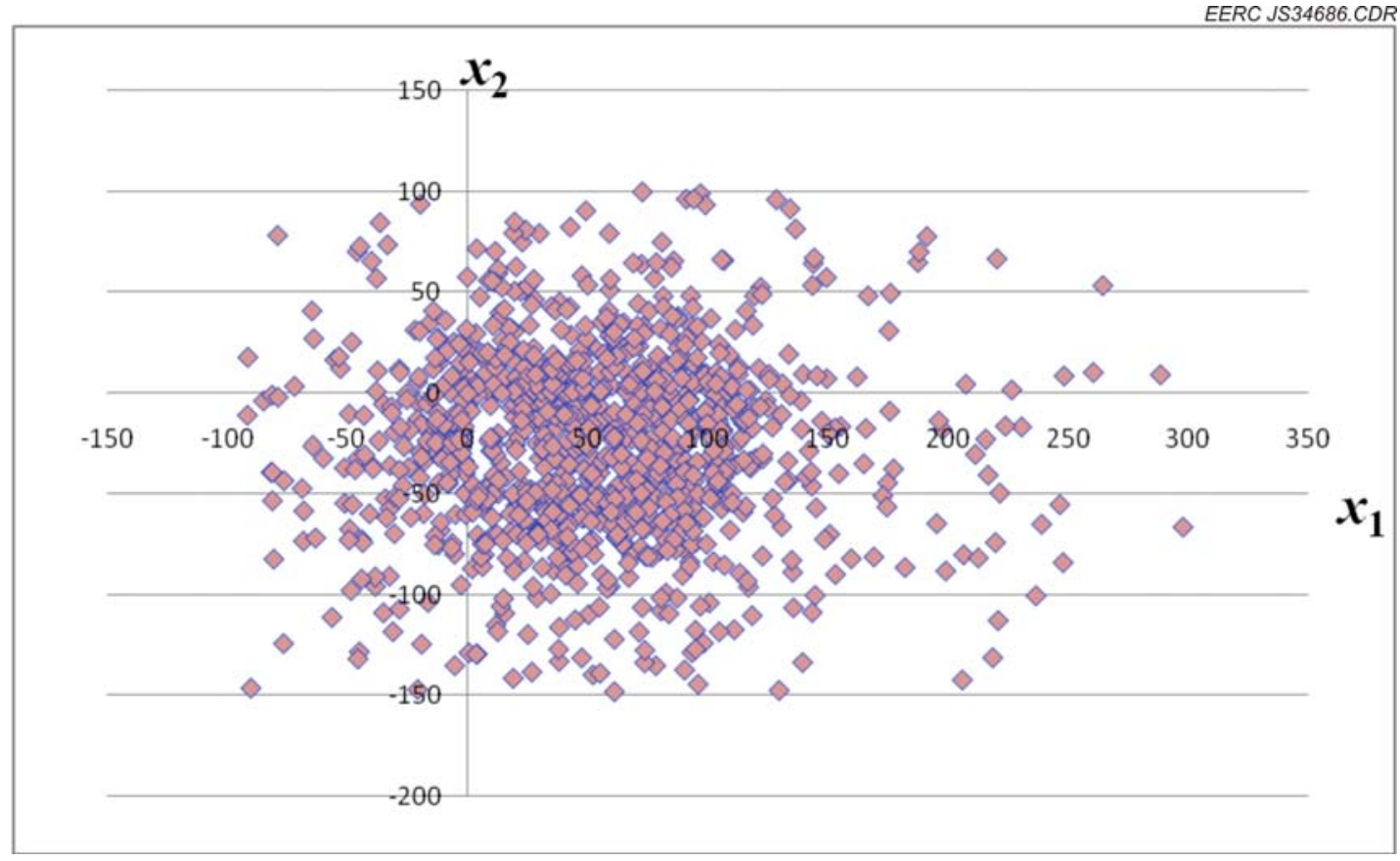

Figure 4. Reconstructed fracture plane and spatial distribution of the events.

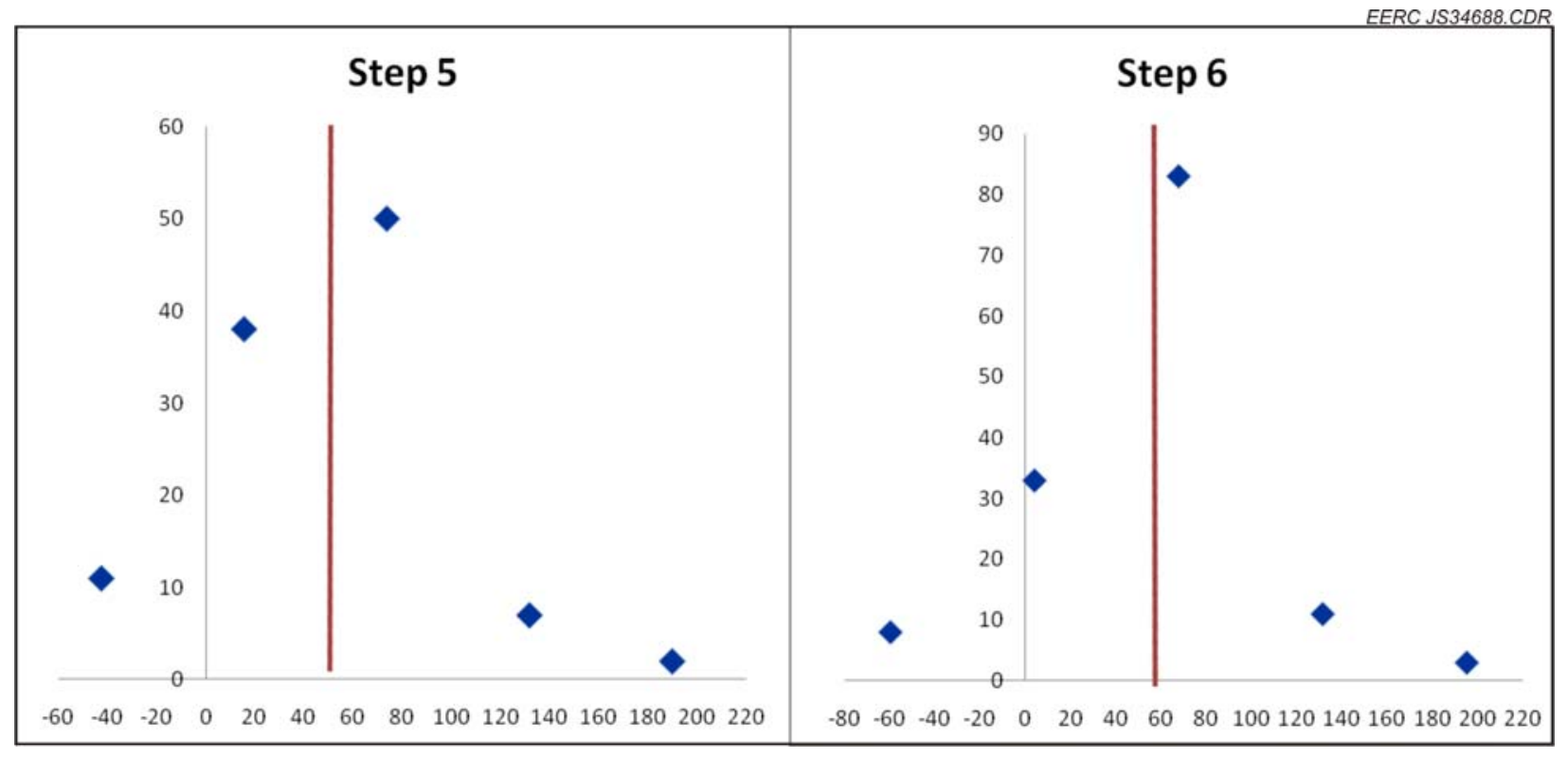

Figure 5. Grouping of the seismic events in steps of fracture propagation. 
events. The working group conducting this project did not have any information on the experimental scheme (e.g., geometry of the specimens and applied mechanical load) used in the laboratory. Both PCA and SRS techniques were utilized for the analysis. The working group was able to draw conclusions on the geometrical parameters of the specimens used in the physical experiment, which were compared to the description later obtained from Professor Labuz. The reconstructed geometry of the fracture created in the physical experiment reasonably reflects failure, which can be expected to occur in response to the applied loads. The analysis and comparison of the laboratory data and numerical results are ongoing, and more details are expected to be available in a joint publication with the working group led by Professor Labuz.

Another result of the numerical experiment pertains to the comparison of the efficiency of PCA and SRS techniques. It was determined that the results obtained by the application of the SRS and PCA method are in good agreement. However, the SRS method provides more detailed information, and, as it seems, more accurate interpretation of microseismic data than the PCA. The methods complement each other. In particular the PCA may serve for the estimation of the reasonable width of the strip ray used in the SRS method.

\section{APPLICATION OF THE TOOL TO THE MICROSEISMIC DATA OBTAINED IN MINES}

Application of the tool to microseismic data recorded in mines serves for additional verification of the efficiency and accuracy of the methodology developed. The possibility of the verification stems from the fact that mining takes place in steps, and the created opening can be numerically treated as a fracture. Reconstructed geometry of the opening can be then compared to the known actual geometry of the mine. Detailed discussion of the data set and its origin is presented in Appendix A and will be kept confidential until the results are published in collaboration with the provider of the data later this year. This section contains the summary of the results obtained. The following conclusions were reached based on the analysis:

- The analysis of the microseismic data indicates that microseismic events group in close proximity to the mining front. This result is in good agreement with the conclusion on the grouping of the events in the vicinity of the fracture front made by simulating microseismicity.

- Both SRS and PCA methods indicate that the midpoint of the events is located in very close proximity to the center of the mined bed, ahead of the mining front. The numerical results obtained for hydraulic fracture indicate that, for a fracture, the midpoint is located at the fracture front. The difference between the results for mining and hydraulic fracture is due to different geometries of the problems: mining creates an opening and, obviously, no seismic events occur in the opening behind the mining front, while the hydraulic fracture stays closed, and events occur both ahead of and behind the fracture front.

- Creation of the opening also results in different groupings of events with respect to the plane of mining development. Similar to hydraulic fracture propagation, the events 
group in the mining plane. However, in contrast with the case of hydraulic fracture growth, there exists another plane of grouping of the events. This plane is perpendicular to the mining plane and coincides with the plane of the mining front. This plane does not exist in the problem of hydraulic fracture growth because the width of the fracture is negligible, while the mining opening has significant width.

- In general, the results of the analysis of data obtained in mines are consistent with the results obtained numerically for hydraulic fracture.

\section{FURTHER APPLICATION OF THE TOOL}

It is expected that the methodology will be used to analyze data of hydraulic fracture monitoring for an ongoing EERC project focused on the evaluation of key factors affecting successful oil production in the Bakken Formation, North Dakota. The microseismic data set is provided by Marathon Oil Company, and the analysis of the data set is one of the key activities of the project.

\section{CONCLUSIONS}

- The basics of numerical simulation of seismicity are applicable to hydraulic fracture.

- Numerical simulation shows that, in accordance with the data of seismic monitoring, the majority of simulated events are microseismic events.

- Attributes of seismicity such as grouping and spatial distribution of the events can be used to determine fracture plane and the location of the fracture front.

- The methodology of the inversion of microseismic data accompanying hydraulic fracture has been developed and implemented into a computer program.

- Verification of the capabilities of the computer program created was conducted using AE data obtained in laboratory experiments and microseismic data recorded in mines.

- Application of the computer code allows reasonable reconstruction of the geometry of mines and fracture created in physical experiments.

\section{REFERENCES}

Daniels, J., DeLay, K., Waters, G., LeCalvez, J., Lassek, J., and Bentley, D., 2007, Contacting More of the Barnett Shale through an integration of real-time microseismic monitoring, petrophysics and hydraulic fracture design: SPE paper 110562. 
Dobroskok, A.A., and Linkov, A.M., 2008, Simulation of seismicity accompanying hydraulic fracture propagation, in 42nd U.S. Rock Mechanics Symposium (USRMS), San Francisco, California, June 29 - July 2, 2008, proceedings.

Du, J., Warpinski, N.R., Davis, E.J., Griffin L G., and Malone, S., 2008, Joint inversion of downhole tiltmeter and microseismic data and its application to hydraulic fracture mapping in tight gas sand formation, in 42nd U.S. Rock Mechanics Symposium (USRMS), San Francisco, California, June 29 - July 2, 2008, proceedings.

King, A., and Talebi, S., 2007, Anisotropy effects on microseismic event location: Pure and Applied Geophysics, v. 164, p. 2142-2156.

Linkov, A.M., 2002, Boundary integral equations in elasticity theory: Dordrecht, The Netherlands, Kluwer, 272 p.

Linkov, A.M., 2005, Numerical modeling of seismic and aseismic events in geomechanics: Journal of Mining Science, v. 41, no. 1, p. 14-26. 4.

Linkov, A.M., 2006, Numerical modeling of seismic and aseismic events in three-dimensional problems of rock mechanics: Journal of Mining Science, v. 42, no. 1, p. 1-14. 6.

Linkov, A.M., 2008, Numerical modeling of fluid flow and fracture propagation under hydraulic fracturing: Journal of Mining Science (in press).

Mahrer, K.D., 1999, A review and perspective on far-field hydraulic fracture geometry studies: Journal of Petroleum Science and Engineering, v. 24, p. 13-28.

Maxwell, S.C., Urbancic, T.I., Prince, M., and Demerling, C., 1993, Passive imaging of seismic deformation associated with steam injection in western Canada: SPE paper 84572.

Maxwell, S.C., and Young, R.P., 1996, International Journal of Rock Mechanics, Mineral Science, and Geomechanics [Abstract], v. 33, no. 7, p. 713-724.

Napier, J.A.L., 2001, Scale effects in the numerical simulation of time-dependent mine seismic activity, in Swets et al. (eds.), International Conference on Rock Mechanics in the National Interest, proceedings: p. 1297-1304.

Riedel J.J., and Labuz, J.F., 2007. Propagation of a shear band in sandstone. International Journal of Numerical Analysis and Meth. Geomechanics. v. 31, p. 1281-1299.

Salamon, M.D.G., 1993, Keynote address - some applications of geomechanical modeling in rockburst and related research, in Young, R.P. (ed.), 3rd International Symposium on Rockbursts and Seismicity in Mines, proceedings: Rotterdam, Balkema, 1993, p. 297-309.

Sellers, E.J., and Napier, J.A.L., 2001, A point kernel representation of large-scale seismic activity in mining, in van Aswegen, G., et al. (eds.), 5th International Symposium on 
Rockbursts and Seismicity in Mines - RaSiM5, proceedings: South African Institute of Mining and Metallurgy, 2001, p. 405-411.

Spottiswoode, S., 2001, Keynote address-synthetic seismicity mimics observed seismicity in deep tabular mines, in van Aswegen, G., et al. (eds.), 5th International Symposium on Rockbursts and Seismicity in Mines - RaSiM5, proceedings: South African Institute of Mining and Metallurgy, 2001, p. 371-377.

Trifu, C., and Shumila. V., 2008, Microseismic monitoring of a controlled collapse at Ocnele Mari, Romania, in 42nd U.S. Rock Mechanics Symposium (USRMS), San Francisco, California, June 29 - July 2, 2008, proceedings.

Urbancic, T.I., and Trifu, C.-I., 2000, Recent advances in seismic monitoring technology at Canadian mines. Journal of Applied Geophysics, v. 45, p. 225-237.

Warpinski, N.R., Griffin, L.G., Davis, E.J., and Grant, T., 2006, Improving hydraulic fracture diagnostics by joint inversion of downhole microseismic and tiltmeter data: SPE paper 102690 .

Wright, C., 2007, Case study-HDTV versus early television - you get to choose: Pinnacle Newsletters, spring 2007. 
APPENDIX A

\section{MICROSEISMIC DATA RECORDED IN A COAL MINE}




\section{MICROSEISMIC DATA RECORDED IN A COAL MINE}

The microseismic data set was obtained from Komsomolskaya Mine in Vorkuta, Russian Federation. Figure A1 presents the plan of longwall mine 712-c in layer 6 of Komsomolskaya. The hatched area corresponds to the parts of the mine created prior to the beginning of microseismic monitoring. The dashed line denotes geological fault. The dip angle of the mined bed approximately equals 2 degrees, the bed thickness is $1.5 \mathrm{~m}$, the length of the mine is $988 \mathrm{~m}$, and the mine progresses in the direction comprising the angle of 170 degrees to the north. The overburden stress at the depth of the mine is $24.7 \mathrm{MPa}$; maximum and minimum horizontal stresses act in the east-west and north-south direction and have magnitudes of 32.1 and 19.8 $\mathrm{MPa}$, respectively. The red dots in Figure A-1 denote the locations of the microseismic events, recorded in the bed plane in February 2008. The total number of recorded events is relatively small at 295 . The energy of $43 \%$ of the events is in the range of 340 to $1000 \mathrm{~J}$; for $33 \%$ of the events, the energy ranges from 1000 to $2000 \mathrm{~J}$; for $17 \%$, it ranges from 2000 to $3500 \mathrm{~J}$; for $4 \%$, it ranges from 3500 to $6000 \mathrm{~J}$, and for 3\% it ranges from 6000 to $11000 \mathrm{~J}$. The majority of the recorded seismic events $(76 \%)$ have the energy below $2000 \mathrm{~J}$, and the average energy is $1800 \mathrm{~J}$. The following seismic attributes were recorded: time of occurrence, location, and energy of the event.

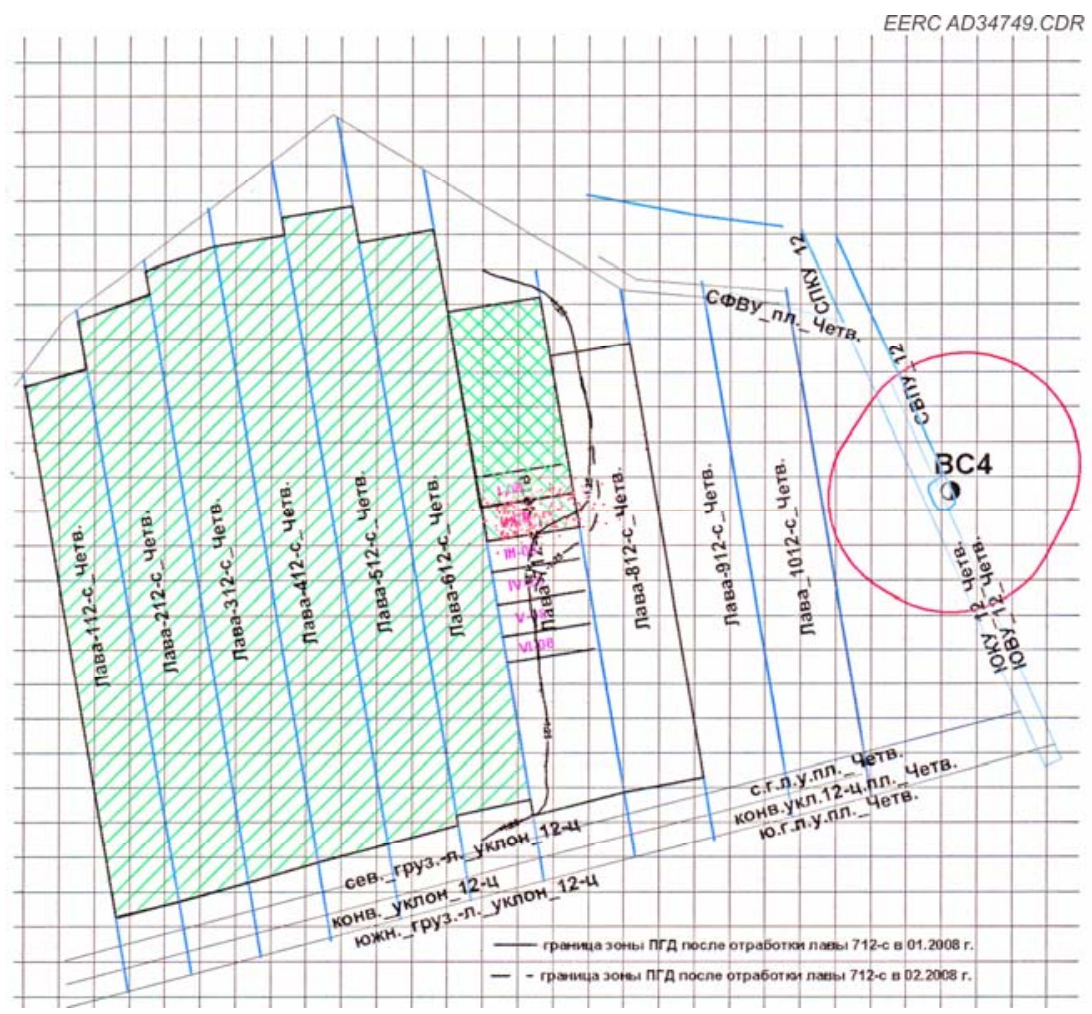

Figure A-1. Outline of longwall mine 712-c Komsomolskaya. 
Figure A-1 shows that the seismic events group in a rectangle, corresponding to the part of the bed mined during the period of monitoring. However, some events took place outside the rectangle in the unmined parts of the bed. Analysis of the coordinates of the seismic events shows that most of them occurred at some $20 \mathrm{~m}$ from the mining plane and have similar distributions in the roof and the floor of the mine.

The analysis of the temporal and spatial distribution of the seismic events resulted in the following conclusions:

- Analysis of the totality of the events does not allow for finding the direction of the propagation because the distribution is too dense in the studied area. Only in breaking the data into groups corresponding to 10-day intervals does it become possible to distinguish the direction of the propagation. It should be noted that, to the authors' knowledge, currently employed commercial analytical methods are applied only to the totality of the events.

- Analysis of the data indicated that the events located remotely from the central point of the events negatively influence the results. Thus the remote events (farther than $300 \mathrm{~m}$ for the considered mine) were excluded from analysis. When eliminating events, both principal component analysis (PCA) and strip ray scanning (SRS) define the plane of propagation quite accurately: the dip angle does not exceed 3.6 degrees even in time steps of some 10 days. The actual dip-angle is near zero.

- When eliminating the remote events, SRS shows that most of the events occur in the narrow strip of half-width $\pm 5 \mathrm{~m}$ near the plane of propagation $(64 \%$ on the first step; $71 \%$ on the second; $75 \%$ on the third).

- When eliminating the remote events, the mean coordinate in the easterly direction remains constant. It is always within the interval from 12,632 to 12,649 . Perhaps, this coordinate corresponds to the middle point of the front line.

- The front line, found by SRS, has coordinates in the northerly direction: 19,975 in the first step, 19,931 in the second step, and 19,878 in the third step. Thus the propagation for 10 days is from 44 to $53 \mathrm{~m}$.

- The corresponding mean values of coordinates in the northerly direction are 19,955, 19,921, and 19,889. The difference for 10 days is from 34 to $32 \mathrm{~m}$.

- The direction of the propagation, found by:

- The SRS estimation is the north-south direction, with a deviation of some $17-23$ degrees to the east.

- The PCA estimation has the deviation of greater magnitude: from 25 to 42 degrees to the east.

- The actual front movement is approximately in the north-south direction. 